\title{
Recent Development of Effect Mechanism of Alloying Elements in Titanium Alloy Design
}

\author{
Lu Jinwen ${ }^{1,2}$, Ge Peng ${ }^{2}$, Zhao Yongqing ${ }^{1,2}$ \\ ${ }^{1}$ Northeastern University, Shenyang 110819, China; ${ }^{2}$ Northwest Institute for Nonferrous Metal Research, Xi'an 710016, China
}

\begin{abstract}
The properties of titanium alloy are determined by the chemical composition and microstructure, and the sorts of alloying elements are the main concerns in alloy design. Titanium can be alloyed with various elements to alter its properties, such as high-temperature performance, creep resistance and formability etc. The main objective of this work is to discuss the effect of alloying elements for processing improvement, microstructure optimization and the alloying principle which should be paid attention to in titanium alloy design. Some problems in new alloy design are also discussed and summarized, especially on the interaction of different alloying elements, which leads to the misfit or misorientation dislocations. The interrelationships between alloying composition, phase stability, microstructure and mechanical properties in several classical titanium alloys are critically reviewed.
\end{abstract}

Key words: titanium alloy design; alloying elements; microstructure; property

Titanium and titanium alloys are extensively used for aerospace, petrochemical and biomedical industries due to their excellent combination of properties: low specific weight, high specific strength, high corrosion resistance, good structural stability and low elastic modulus ${ }^{[1,2]}$. Since the past few years, titanium alloys have continued to develop greatly and become one of very important structure materials. With the expansion of their application, the application environment becomes more and more complex, and the demand for the titanium alloys with special properties (such as high temperature titanium alloys, corrosion resistant titanium alloys, structural titanium alloys, functional titanium alloys, burn resistant titanium alloys, high strength and high toughness titanium alloys, etc.) is increasingly outstanding. In China, a series of titanium alloys have been developed and applied, such as TC9, Ti600, TC21, TB6, TA5, TA9, Ti40, Ti14, but they still can not meet the needs of industries fully ${ }^{[3-8]}$.

The properties of titanium alloys are determined by two factors: chemical composition and microstructure ${ }^{[1,9]}$. The types and amount of alloying elements are the main concerns in alloy design. The chemical composition of the titanium alloys primarily determines the properties and volume fraction of the phases. Due to the limited deformation capability of hexagonal dense packed crystal structures, $\alpha$ is less ductile than the body-centered cubic $\beta$. Titanium can be alloyed with a variety of elements to alter its properties, for improving strength, high-temperature performance, creep resistance, weldability and formability. Depending on their influence on the $\beta$-transus temperature, the alloying elements of titanium are classified as neutral, $\alpha$-stabilizers, and $\beta$-stabilizers. The principal alloying element in alpha alloys is $\mathrm{Al}$, the major neutral element is $\mathrm{Zr}$ and two types of $\beta$ stabilizers are known as the eutectoid and the isomorphous ${ }^{[1,10]}$. The isomorphous stabilizers include $\mathrm{Mo}, \mathrm{V}, \mathrm{Ta}$ and $\mathrm{Nb}$ and the eutectoid stabilizers include $\mathrm{Cr}, \mathrm{Mn}, \mathrm{Fe}, \mathrm{Co}, \mathrm{Ni}$ and $\mathrm{Cu}$. As the research of titanium alloy continues to deepen, alloying elements play a crucial role in titanium design. The different types of alloying elements and their amount will influence the mechanical property and application of the alloy ${ }^{[1-16]}$.

The main objective of this work is to discuss the effect of alloying elements and to present the principle which should be paid attention to in titanium alloy design. Some problems existing in new alloy design will also be discussed and summarized, especially on the interaction of different alloying

Received date: April 11, 2013

Foundation item: National Basic Research Development Program of China (2007CB613805)

Corresponding author: Zhao Yongqing, Professor, Northwest Institute for Nonferrous Metal Research, Xi'an 710016, P. R. China, Tel: 0086-29-86231078, E-mail: trc@c-nin.com

Copyright (C) 2014, Northwest Institute for Nonferrous Metal Research. Published by Elsevier BV. All rights reserved. 
elements, which leads to the misfit or misorientation dislocations. The interrelationships among alloying composition, stability, microstructure and mechanical properties in several classical titanium alloys were critically reviewed. It is hoped to deeply understand the influencing mechanism of alloy elements in titanium alloy design, and provide reference for the design and research of new titanium alloys.

\section{$1 \alpha$-Stabilizing Elements}

The alloying elements of $\alpha$-stabilizers include Al, Ga, C, N and $\mathrm{O}$, however among them $\mathrm{Al}$ is the main element in titanium alloy design. By alloying with $\alpha$-stabilizing elements (especially $\mathrm{Al}$ ), it is possible to increase the melting point, obtain the required percentage of $\alpha$ platelets for strengthening or bimodal microstructures for fatigue property improvement, and lessen the reactivity of titanium, thus facilitating the casting process.

According to Ti-Al phase diagram ${ }^{[17]}$ apart from $\alpha$ and $\beta$ phases, which are of central importance for the conventional titanium alloys, several intermetallic phases are presented, such as $\alpha_{2}-\mathrm{Ti}_{3} \mathrm{Al}, \gamma$-TiAl, $\mathrm{TiAl}_{2}$ and $\mathrm{TiAl}_{3}$. Adding $\mathrm{Al}$ to titanium alloys can increase beta transition temperature, as well as enhance the solubility of $\beta$ stabilizing elements in $\alpha$ phase. Al atom of $\alpha$ phase exists in the form of replacement. Titanium alloy with aluminum content of (6 7) wt $\%$ has a high thermostability and a good welding performance. When the Al content exceeds the solubility limit of $\alpha$ phase, the ordered $\alpha_{2}$ phase based on $\mathrm{Ti}_{3} \mathrm{Al}$ appears, and the alloy becomes brittle and exhibits a lower thermal stability. Therefore, when new alloys are to be developed, the contents of Al should not to exceed $9 \%$ which is the so-called aluminum-equivalent, otherwise the alloy-embrittling intermetallic compound $\mathrm{Ti}_{3} \mathrm{Al}$ would be precipitated. Recent years, because of the large activities on titanium aluminides, this borderline has been crossed. Scientists and engineers have learned to take the advantage of the extraordinary properties of intermetallic compounds on the basis of $\alpha_{2}-\mathrm{Ti}_{3} \mathrm{Al}$ and $\gamma$-TiAl to improve the burn resistance of the $\mathrm{Ti}$ alloy at high temperature. For example, the ignition temperature of the intermetallic compounds $\left(900 \sim 1050{ }^{\circ} \mathrm{C}\right)$ is higher than those of Ti13 Cu alloy $\left(900{ }^{\circ} \mathrm{C}\right)$, Ti-8Mo alloy $\left(900{ }^{\circ} \mathrm{C}\right)$ and Ti-6Al-4V alloy $\left(750{ }^{\circ} \mathrm{C}\right)^{[24]}$

Since recent decades, many researchers have greatly investigated the effects of $\mathrm{Al}$ on the microstructures and mechanical properties of titanium alloy and achieved remarkable successes. The effects of ternary alloying elements on the shape memory behavior of Ti-Ta alloys were investigated by Buenconsejo et $\mathrm{al}^{[18]}$. The results showed that adding of $\mathrm{Al}$ or $\mathrm{Sn}$ to Ti-Ta alloy could effectively weaken the effect of the shape memory behavior of the alloys, because it suppressed the formation of $\omega$ phase during aging treatment. Therefore, Ti-30Ta-1Al alloy exhibited a stable high-temperature shape memory effect during thermal cycling. $\mathrm{Li}^{[19]}$ studied the structure and the stability of the precipitates in $500{ }^{\circ} \mathrm{C}$ exposed $\mathrm{Ti}-25 \mathrm{~V}-15 \mathrm{Cr}-x \mathrm{Al}$ alloys. When the $\mathrm{Al}$ content varied from $2 \mathrm{wt} \%$ to $4 \mathrm{wt} \%$, the precipitation increased and the kinetics of $\alpha$ to $\alpha_{2}$ ordering moved fast. A high volume fraction of precipitates was found in the alloys with higher Al levels. Fig.1 shows a small amount of the precipitates on grain boundaries in the sample of $\mathrm{Ti}-25 \mathrm{~V}-15 \mathrm{Cr}-3 \mathrm{Al}$ alloy which were grown into platelets after the solution treatment at $1050{ }^{\circ} \mathrm{C}$ for $30 \mathrm{~min}$ followed by ageing at $700{ }^{\circ} \mathrm{C}$ for $4 \mathrm{~h}$. During the last decade, an intensive research has been performed on the titanium aluminum intermetallic alloys by $\mathrm{Cao}^{[20]}$, $\mathrm{Liu}^{[21]}$, Huang ${ }^{[22]}$, Wang ${ }^{[23]}$ and $\mathrm{Ye}^{[24]}$, et al. The results showed that high temperature and high strength Ti-Al alloys could be obtained via dispersive strengthening effect from fine $\mathrm{Ti}_{3} \mathrm{Al}$ precipitates $\left(\alpha_{2}\right)$ and solution strengthening effect from other alloying elements. Fig. 2 shows a typical microstructure prior to and after tensile deformation at high temperatures for Ti-45Al-3Nb-0.5Sc alloy. The acicular $\alpha_{2}$ precipitates along $\alpha / \beta$ phase boundaries which formed during air cooling process after homogenization in the $(\alpha+\beta)$ two-phase field were resulting in the specific thermomechanical history of the alloy or the fast ordering kinetics or anisotropic diffusion of $\mathrm{Al}$. However, some problems of the effect of $\mathrm{Al}$ in new alloy design still need the further investigation.

\section{Neutral Elements}

The neutral elements include $\mathrm{Zr}$ and $\mathrm{Hf}$, however $\mathrm{Zr}$ is the major neutral element in titanium alloy design. Neutral elements only have a minor influence on the $\beta$-transus temperature. As viewed from Ti-Zr phase diagram ${ }^{[17]}, \mathrm{Zr}$ has a high solubility both in $\alpha$ and $\beta$ titanium, and even is able to
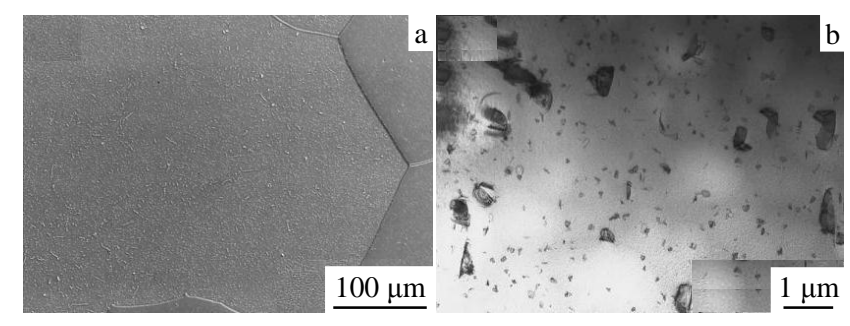

Fig.1 SEM (a) and TEM (b) micrographs of a Ti-25V-15Cr-3Al sample after solution treatment at $1050^{\circ} \mathrm{C}$ for $30 \mathrm{~min}$ followed by aging at $700^{\circ} \mathrm{C}$ for $4 \mathrm{~h}$, showing platelets of $\alpha$ precipitates

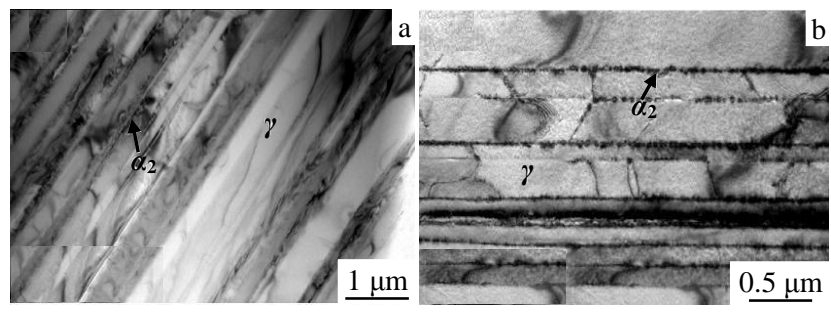

Fig.2 TEM substructures for Ti-45Al-3Nb-0.5Sc alloys (a) prior to high temperature tensile test and (b) after $900{ }^{\circ} \mathrm{C}$ tensile test 
form infinite solid solution. $\mathrm{Zr}$ can reduce the volume percentage of $\omega$ phase in aging by stabilizing $\beta$-phase in near $\beta$ and metastable $\beta$ alloys. Therefore, $\mathrm{Zr}$ has nearly no influence on the $\alpha / \beta$ phase boundary, but primarily strengthens $\alpha$ phase and improves thermostability and welding performance. The investigations of Geetha ${ }^{[25]}$, Wang ${ }^{[26]}$, Akahori ${ }^{[27]}$, Crema$\mathrm{sco}^{[28]}$ and Kurode's ${ }^{[29]}$ were concerned with the influences of non-toxic element $\mathrm{Zr}$ addition in titanium alloys. Their results showed that the titanium alloys composed of $\mathrm{Zr}$ exhibit lower modulus of elasticity, higher strength and corrosion resistance for implant materials. Fig.3 presents optical micrographs of $\mathrm{Ti}-35 \mathrm{Nb}$ and $\mathrm{Ti}-25 \mathrm{Nb}-15 \mathrm{Zr}$ alloys, illustrating the influence of the content of $\mathrm{Zr}$ on the phases formed. $\mathrm{Li}^{[30]}$ made a systematic study of Ti-24Nb-4Zr-7.9Sn alloy, which shows a higher strength because the reversible transformation to $\alpha$ " martensite was effectively suppressed by alloying with $\mathrm{Zr}$ and $\mathrm{Sn}$. The effects of chromium addition on the structure and the mechanical properties of Ti-10Zr alloy were reported by Cheng et $\mathrm{al}^{[31]}$. They pointed out that the Ti-10Zr alloy was mainly composed of $\alpha^{\prime}$-phase. Compared to most of other alloy systems $\mathrm{Zr}$ in titanium alloys could offer a superior corrosion resistance, and a good biocompatibility across a wide range of environment, but its strength and elastic recovery were not sufficient for applications.

\section{$3 \beta$-Stabilizing Elements}

$\beta$-stabilizing elements can be subdivided into $\beta$-isomorphous and $\beta$-eutectic elements. The former includes Mo, V, Ta and $\mathrm{Nb}$ and the later includes $\mathrm{Cr}, \mathrm{Mn}, \mathrm{Fe}, \mathrm{Co}, \mathrm{Ni}$ and $\mathrm{Cu}$. $\beta$-stabilizing elements shift the $\beta$ phase field to lower temperatures due to the formation of intermetallic compounds with $\mathrm{Ti}$ ( $\beta$-eutectic elements) and their much higher solubility in titanium ( $\beta$-isomorphous elements). Depending upon the amount of $\beta$ stabilizers presenting in an alloy, the molybdenum equivalency of the $\beta$ stabilizer is used to assess the level of the element necessary to prevent martensitic transformation upon quenching to room temperature. The molybdenum equivalency is the ratio of the level of a given stabilizer to the level of molybdenum required for the same degree of $\beta$ stability. In general, a molybdenum equivalency of $10 \%$ is required to stabilize the $\beta$ phase upon quenching. In this section, the effect of the isomorphous stabilizers of Mo and V and the eutectoid stabilizers including $\mathrm{Cr}$ and $\mathrm{Fe}$ in titanium

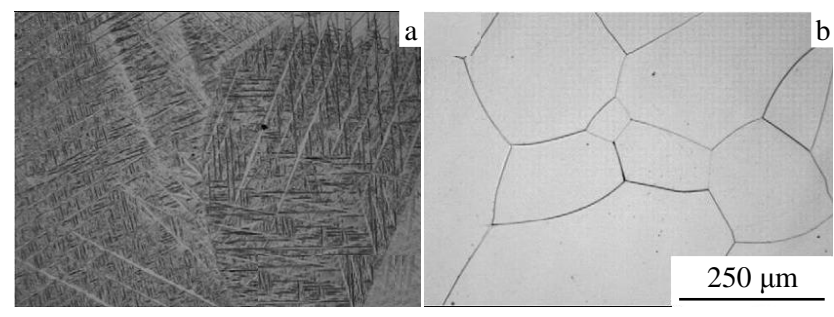

Fig.3 Optical micrographs of Ti-35Nb alloy (a) and Ti-25Nb-15Zr alloy (b) alloy design will be discussed and summarized.

According to Ti-Mo phase diagram ${ }^{[17]}$. it is clear to see that Mo and $\beta$-Ti have nearly the same crystal lattice and are able to form infinite solid solution in $\beta$-Ti. With the decrease of temperature, the solubility of Mo in $\beta$-Ti increases. When the solubility of Mo exceeds $12 \%$ at $695{ }^{\circ} \mathrm{C}$, a single $\beta$-solid solution will be formed. Adding Mo in titanium alloys can increase the strength and improve the plastic property. $\mathrm{Ho}^{[32]}$, Chen ${ }^{[33]}$ and $\operatorname{Min}^{[34]}$ studied microstructures and the properties of Ti-Mo titanium alloys. It was shown that the increase of Mo content is propitious to the crystal refinement and the improvement of plasticity of Ti-Mo alloys. When the Mo content is $5 \%$, the hexagonal $\alpha^{\prime}$ phase and the retained $\beta$ grain boundary can be observed. When the Mo content is $10 \%, \beta$ phase will be detected. When the Mo contents are $15 \%$ and $20 \%$, only equiaxed $\beta$ grains are observed. Fig.4 shows the optical micrograph and SEM backscattered electron image of Ti-15Mo alloy after solution treatment plus aging at $873 \mathrm{~K}$ for $3.6 \mathrm{ks}$, in which $\alpha$ phase precipitation is observed, and $\alpha$ phase precipitates are relatively coarse after aging treatment. Work by $\mathrm{Ho}^{[35,36]}$ showed that $\mathrm{Ti}-5 \mathrm{Cr}-7 \mathrm{Mo}$, Ti-5Cr-9Mo and Ti-5Cr$11 \mathrm{Mo}$ alloys exhibited ductile properties, and the Ti-5Cr-9Mo alloy with $\beta$ phase displayed the lowest bending modulus. However, the Ti-5Cr-3Mo and Ti-5Cr-5Mo alloys had much higher bending moduli due to the formation of the $\omega$ phase during quenching.

According to Ti-V phase diagram ${ }^{[17]}$ it can be seen that the binary system Ti-V and Ti-Mo have almost the same phase transformation in solid state. $\mathrm{V}$ and $\beta$-Ti also possess the almost the same crystal lattice and form infinite solid solution. With the decrease of temperature, the solubility of $\mathrm{V}$ in $\beta$-Ti also increases. When the solubility of $\mathrm{V}$ exceeds $18 \%$ at $675{ }^{\circ} \mathrm{C}$, a single $\beta$-solid solution can be formed. Adding V in titanium alloys not only decreases the distortion of lattice but also improves the structure stability. Zhao's ${ }^{[37]}$ study pointed out, with the increase of $\mathrm{V}$ content, the creep resistance of the alloy decreased, the thermal stability was improved and grains grew, which was mainly attributed to the characteristics of $\mathrm{V}$ and its smaller atomic radius compared with that of titanium.

Ti-Cr phase diagram ${ }^{[17]}$ showed that $\mathrm{Cr}$ and $\beta$-Ti will form an infinite solid solution. The eutectoid stabilizer $\mathrm{Cr}$ decreases the temperature of $\alpha / \beta$ phase transformation and stabilizes $\beta$

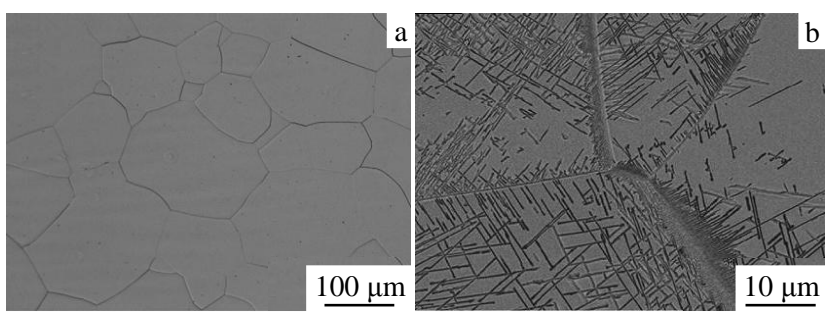

Fig.4 Ti-15Mo alloy after solution treatment plus aging at $873 \mathrm{~K}$ for $3.6 \mathrm{ks}$ : (a) optical micrograph and (b) SEM backscattered electron image 
phase. When the temperature arrives at $667{ }^{\circ} \mathrm{C}$, the eutectoid reaction takes place as follows and the maximum solubility of $\mathrm{Cr}$ in $\alpha$-Ti reaches $0.5 \mathrm{wt} \%$ :

$$
\beta \leftrightarrow \alpha+\mathrm{TiCr}_{2}
$$

Work by Zhao ${ }^{[38]}$ showed that the burn resistance of $\mathrm{Ti}-\mathrm{Cr}$ alloy is improved when the $\mathrm{Cr}$ content is more than $10 \%$, especially more than $15 \%$, due to that the interface of the alloy is enriched with $\mathrm{Cr}$, and $\mathrm{Cr}$-oxides have a tenacious ability, which can retard the oxygen diffusion into the matrix and decrease the burning velocity. Cheng's study ${ }^{[39]}$ showed that Ti-Cr system alloys obviously had different structures and mechanical properties upon adding various amounts of $\mathrm{Cr}$. When $3 \% \mathrm{Cr}$ was added, the retention of the metastable $\beta$-phase began. When $5 \%$ or more $\mathrm{Cr}$ was added, the $\beta$-phase with a bcc crystal structure was almost entirely retained. The largest quantity of $\omega$-phase and the highest bending modulus were found in the Ti-10Zr-5Cr alloy; however, its bending strength was slightly lower than those containing no $\omega$-phase (Ti-10Zr-1Cr and Ti-10Zr-10Cr) due to premature and brittle fractures.

According to Ti-Fe phase diagram ${ }^{[17]}$, when the temperature arrives at $1085{ }^{\circ} \mathrm{C}$, the following eutectoid reaction takes place and the maximum solubility of $\mathrm{Fe}$ in $\beta$-Ti is $32 \%$.

$$
\beta \leftrightarrow \alpha+\mathrm{TiFe}
$$

Work by $\mathrm{Lin}^{[40]}$ and $\mathrm{Hsu}^{[41]}$ showed that Ti-Fe system alloys possessed different structures and mechanical properties depending upon the various addition of Fe. When $1 \%$ or more iron was added, the entire alloy became that with equiaxed $\beta$ phase structure and its grain size decreased with increasing of iron content. Athermal $\omega$ phase was formed in alloys containing iron roughly between $0.5 \%$ and $3 \%$. However, when $4 \%$ Fe or more was added, the $\beta$ phase with a bcc crystal structure was entirely retained. Fig.5 shows the optical micrographs of Ti-7.5Mo and Ti-7.5Mo- $x \mathrm{Fe}$ alloys, which show that the grain sizes in Ti-7.5Mo- $x \mathrm{Fe}$ alloys decreased

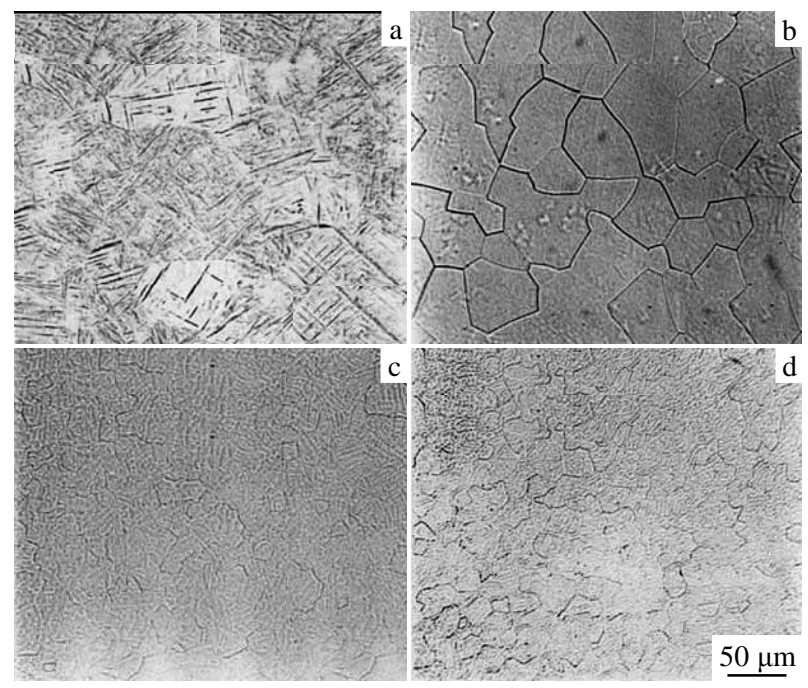

Fig.5 Optical micrographs of Ti-7.5Mo (a), Ti-7.5Mo-1Fe (b), Ti-7.5Mo-3Fe (c), and Ti-7.5Mo-5Fe (d) alloys with increasing of iron content. Mao's research ${ }^{[42]}$ pointed out that the steady-state creep rate, the $1 \%$ creep-strain lifetime and the transient creep behavior of Ti-22Al-11Nb-2Mo- $1 \mathrm{Fe}$ were improved in comparison with that of Ti-22Al-27Nb. The additions of $\mathrm{Fe}$ and Mo enhanced the activation energy of self-diffusion in the $\mathrm{Ti}_{2} \mathrm{AlNb}$-based alloy. The alloy also exhibited high $0.2 \%$ yield strength and ultimate tensile strength at high temperatures.

\section{Summary}

Alloying elements are added into titanium alloys for processing improvement or microstructure optimization. $\beta$ phase stabilizers, such as Mo, V, Gr and Fe, are added for widening the $\beta$ phase region to improve processability. $\alpha$ phase stabilizers, such as $\mathrm{Al}$, are added to obtain the required percentage of $\alpha$ phases for strengthening or bimodal microstructures for fatigue property improvement. Neutral elements, such as $\mathrm{Zr}$, are added to improve the plasticity. However, the current understanding of the effect of alloying elements are only to be regarded as preliminary findings for the alloy design, and the detailed mechanism is not very clear yet. Therefore, the direct or indirect relationship between all kinds of alloying elements and mechanical properties (such as strength, plasticity, fracture toughness, fatigue, etc) needs to be systemically proceeded.

\section{References}

1 Leyens C, Peters M. Titanium and Titanium Alloys[M]. Weinheim: Wiley-VCH, 2003

2 Wang X, Jahazi M, Yue S. Mater Sci Eng A[J], 2008, 492: 450

3 Yu W X, Li M Q, Luo J. Mater Sci Eng A[J], 2010, 527: 4210

4 Zhang J, Li D. Mater Sci Eng A[J], 2003, 341: 229

$5 \mathrm{Ng}$ H P, Douguet E, Bettles C J et al. Mater Sci Eng A[J], 2010, 527: 7017

6 Ankem S, Greene C A. Mater Sci Eng A[J], 1999, 263: 127

7 Niinomi M. Science and Technology of Advanced Materials[J], 2003, 4: 445

8 Zhang S Z, Xu H Z, Li G P et al. Mater Sci Eng A[J], 2005, 408: 290

9 Paladugu M, Kent D, Wang G et al. Mater Sci Eng A[J], 2010, 527: 6601

10 Ohmori Y, Ogo T, Nakai K et al. Mater Sci Eng A[J], 2001, 312: 182

11 Wain N, Hao X J, Ravi G A et al. Mater Sci Eng A[J], 2010, 312: 7673

12 Zong Y Y, Shan D B, Luo Y S. International Journal of Hydrogen Energy[J], 2009, 34: 4900

13 Liu H J, Zhou L, Liu P et al. International Journal of Hydrogen Energy[J], 2009, 34: 9596

14 Zhang S Z, Xu H Z, Li G P et al. Mater Sci Eng A[J], 2005, 408: 290

15 Ouchi C, Iizumi H, Mitao S. Mater Sci Eng A[J], 1998, 243: 186

16 Wei Q Q, Wang L Q, Fu Y F et al. Materials and Design[J], 
2011, 32: 2934

17 Massalski I, Thaddeus B. Binary Alloy Phase Diagrams[M]. New York: AMS, Metals Park, 1986

18 Buenconsejo P J S, Kim H Y, Miyazaki S. Acta Materialia[J], 2009, 57: 2509

19 Li Y G, Blenkinsop A B, Loretto M H et al. Acta Materialia[J], 1998, 46: 5777

20 Cao L, Wang H W, Zou C M et al. J Alloy Compd[J], 2009, 484: 816

21 Liu J, Luan Q D, Wang X G et al. Mater Sci Eng A[J], 2010, 527: 7658

22 Huang A J, Li G P, Hao Y L et al. Acta Materialia[J], 2003, 51: 4939

23 Wang J N, Zhu J, Wu J S et al. Acta Materialia[J], 2002, 50: 1307

24 Ye H Q. Mater Sci Eng A[J], 1999, 263: 289

25 Geetha M, Mudali U K, Gogia A K et al. Corrosion Science[J], 2004, 46: 877

26 Wang L Q, Yang G J, Yang H B et al. Rare Metal Materials and Engineering[J], 2009, 38(4): 579 (in Chinese)

27 Akahori T, Niinomi M, Fukui H et al. Mater Sci Eng C[J], 2005, 25: 248

28 Cremasco A, Messias A D, Esposito A R et al. Mater Sci Eng $C[\mathrm{~J}], 2011,31: 186$

29 Kurode D, Niinomi M, Morinaga M et al. Mater Sci Eng A[J],
1998, 243: 244

30 Li S J, Zhang Y W, Sun B B et al. Mater Sci Eng A[J], 2008, 480: 101

31 Cheng C H, Hsu H C, Wu S C et al. J Alloy Compd[J], 2009, 481: 524

32 Ho W F, Ju C P, Lin J H C. Biomaterials[J], 1999, 20: 2115

33 Chen Y Y, Xu L J, Liu Z G et al. Trans Nonferrous Met Soc China[J], 2006, 16(S): 824

34 Min X H, Emura S, Nishimura T et al. Mater Sci Eng A[J], 2010, 527: 1480

35 Ho W F, Wu S C, Chang H H et al. Mater Sci Eng C[J], 2010, 30 : 904

36 Ho W F, Cheng C H, Pan C H et al. Mater Sci Eng C[J], 2009, 29: 36

37 Zhao Y Q, Xin S W, Zeng W D. J Alloy Compd[J], 2009, 481: 190

38 Zhao Y Q, Zhou L, Deng J. J Alloy Compd[J], 1999, 284: 190

39 Cheng C H, Hsu H C, Wu S C et al. J Alloy Compd[J], 2009, 484: 524

40 Lin D J, Lin J H C, Ju C P. Biomaterials[J], 2002, 23: 1723

41 Hsu H C, Hsu S K, Wu S C et al. Materials Characterization[J], 2010, 61: 851

42 Mao Y, Hagiwara M, Emura S. Scripta Materialia[J], 2007, 57: 261

\title{
钛合金设计中合金元素影响机理的研究进展
}

\author{
卢金文 ${ }^{1,2}$, 葛 鹏 $^{2}$, 赵永庆 ${ }^{1,2}$ \\ (1. 东北大学, 辽宁 沈阳 110819)
}

(2. 西北有色金属研究院, 陕西 西安 710016)

\begin{abstract}
摘 要: 钛合金的性能主要取决于合金成分和显微组织两方面, 而合金元素的种类选择以及添加量是合金成分设计的主要组成内容, 不 同合金元素的添加可以一定程度上改善合金的强度，高温性能，蠕变性能以及加工性能等，满足特殊工业需求。主要探讨了合金元素在 钛合金设计中的作用以及说明了各合金元素在新合金设计中应注意的一些原则, 并对合金元素在钛合金设计中存在的一些问题进行探讨 和归纳总结, 特别对于合金中不同合金元素之间的相互作用, 引起合金组织中位错取向和相组成发生变化, 从而影响合金的机械性能。 另外, 对几种经典合金的合金组成、稳定性以及组织性能之间的相互关联进行研究, 希望进一步了解合金元素在钛合金中的影响机理, 为新型钛合金设计与研发提供参考。
\end{abstract}

关键词: 钣合金设计; 合金元素; 显微组织; 性能

作者简介：卢金文，男，1984 年生，博士生，西北有色金属研究院，陕西 西安 710016，电话：029-86231078，E-mail: lujwen@163.com 